\title{
ОЧИСТКА РАСТВОРОВ ОТ ИОНОВ НИКЕЛЯ ПРИ ИСПОЛЬЗОВАНИИ В КАЧЕСТВЕ КОАГУЛЯНТА ХЛОРИДА ЖЕЛЕЗА(ІІІ)
}

\author{
О. Д. Линников, И.В. Родина \\ ОЛЕГ ДМИТРИЕВИЧ ЛИННИКОВ - д.х.н., заведующий лабораторией неорганического синтеза институ- \\ та химии твердого тела Уральского отделения Российской академии наук. E-mail: linnikov@mail.ru.
}

ИРИНА ВАСИЛЬЕВНА РОДИНА - инженер 1-й категории лаборатории неорганического синтеза Института химии твердого тела Уральского отделения Российской академии наук.

620990, Россия, г. Екатеринбург, Первомайская ул., 91. Институт химии твердого тела Уральского отделения Российской академии наук.

Показано, что использование в качестве коагулянтахлорида железа(III) позволяет очищать загрязнённые растворы не только от нерастворимых грубодисперсных и коллоидных примесей, но также и от присутствуюших в них ионов никеля. Исследования были проведень при комнатной температуре на модельном растворе сульфата натрия (400 мг/л), имитирующем загрязнённые природные и сточные воды. Установлено, что удаление ионов никеля из модельного раствора образующиимя в нём осадком гидроксида железа(III) при рН 7 и 8 с удовлетворительной точностью описывается уравнением Ленгмюра для мономолекулярной адсорбции. Наиболее полно удаление ионов никеля из раствора происходит при осаждении гидроксида железа(III) при рН =8. Полученные данные позволяют подбирать требуемую концентрацию коагулянта $\mathrm{FeCl}_{3}$ для достижения заданной глубины очистки загрязнённых растворов от ионов никеля.

Ключевые слова: коагулянты, хлорид железа(III), никель, соосаждение, сорбция, уравнение Ленгмюра.

\section{PURIFICATION OF SOLUTIONS FROM NICKEL IONS WHEN USING IRON(III) CHLORIDE AS A COAGULANT}

\author{
O. D. Linnikov, I. V. Rodina
}

91, Pervomaiskaya St., GSP, 620990, Ekaterinburg. Institute of Solid State Chemistry of the Ural Branch of the Russian Academy of Sciences.

It has been shown that the use of iron (III) chloride as a coagulant makes it possible to clean contaminated solutions not only from insoluble coarse and colloidal impurities, but also from nickel ions present in them. The studies were carried out at room temperature on a model sodium sulfate solution $(400 \mathrm{mg} / \mathrm{L})$, which simulated polluted natural and waste waters. It was found that the removal of nickel ions from the model solution by the precipitate of iron (III) hydroxide formed in it at pH 7 and 8 is described with satisfactory accuracy by the Langmuir equation for monomolecular adsorption. The most complete removal of nickel ions from the solution occurs during the precipitation of iron (III) hydroxide at $\mathrm{pH}=8$. The data obtained make it possible to select the required concentration of the coagulant $\mathrm{FeCl}_{3}$ to achieve the specified depth of purification of contaminated solutions from nickel ions.

Keywords: coagulants, iron (III) chloride, nickel, coprecipitation, sorption, Langmuir equation. 
Неорганические коагулянты уже давно используются для очистки природных и сточных вод от нерастворимых грубодисперсных и коллоидных примесей [1-3]. Объёмы их потребления остаются высокими на протяжении уже многих десятилетий. Это связано с тем, что данные реагенты позволяют существенно упростить и ускорить процесс очистки загрязнённых вод и улучшить их качество.

Из известных неорганических коагулянтов для очистки загрязнённых вод наибольшее применение нашли коагулянты на основе солей железа и алюминия. Так, коагулянты на основе солей железа $\left(\mathrm{FeSO}_{4}, \mathrm{Fe}_{2}\left(\mathrm{SO}_{4}\right)_{3}\right.$ и $\left.\mathrm{FeCl}_{3}\right)$ обладают хорошими коагулирующими свойствами и работают в широком диапазоне $\mathrm{pH}$ [1-3]. Они не чувствительны к температуре очищаемой воды и могут использоваться для осветления вод различного солевого состава. Однако при их применении очень часто возникает необходимость дополнительного подщелачивания очищаемого раствора, так как при гидролизе солей железа он подкисляется, и может произойти сдвиг его рН в кислую область.

Последнего недостатка в какой-то степени лишены коагулянты на основе солей алюминия. К ним относятся $\mathrm{AlCl}_{3}, \mathrm{Al}_{2}\left(\mathrm{SO}_{4}\right)_{3}$ и оксихлориды алюминия различной основности $\left(\mathrm{Al}(\mathrm{OH}) \mathrm{Cl}_{2}, \mathrm{Al}(\mathrm{OH})_{2} \mathrm{Cl}\right.$, $\mathrm{Al}_{2}(\mathrm{OH})_{5} \mathrm{Cl}$ и т.п.). Данные коагулянты также хорошо очищают воду от коллоидно-дисперсных взвесей. Существенным недостатком алюмосодержащих коагулянтов является то, что они малоэффективны при низкой температуре раствора и работают в достаточно узком диапазоне рН [1-3]. Кроме того, их применение приводит к появлению ионов алюминия в очищаемой воде, что отрицательно влияет на здоровье людей [2, 4]. В некоторых случаях они по эффективности существенно уступают коагулянтам на основе солей железа $[5,6]$.

Из литературы известно, что наряду с удалением из воды коллоидно-дисперсных загрязнений неорганические коагулянты могут очищать воду и от истинно растворённых веществ, в частности, ионов тяжёлых металлов [1-3]. Однако данные о каких-либо количественных характеристиках этого процесса в литературе отсутствуют, что затрудняет подбор типа и дозы коагулянта для удаления из растворов таких нежелательных примесей. Настоящая работа является попыткой заполнить этот пробел. В ней исследовано влияние такого достаточно широко используемого неорганического коагулянта, как хлорное железо $\left(\mathrm{FeCl}_{3}\right)$, на очистку раствора от ионов никеля при рН 7 и 8. Ионы никеля, как известно, имеют очень низкие ПДК для питьевой воды (0,1 мг/л), а также для вод рыбохозяйственного назначения $(0,01$ мг/л), что де- лает проблему очистки растворов от них очень актуальной. Выбор же значений рН 7 и 8 для проведения очистки обусловлен требованиями нормативных документов для химического состава питьевой воды и вод, сбрасываемых в водоёмы рыбохозяйственного значения.

\section{Экспериментальная часть}

Исследования проводили в лабораторных условиях при комнатной температуре $\left(25 \pm 2{ }^{\circ} \mathrm{C}\right)$ на модельном растворе, имитирующем природные и сточные воды, который готовили путём смешения в дистиллированной воде заданных объёмов растворов сульфатов натрия и никеля $\left(\mathrm{Na}_{2} \mathrm{SO}_{4}\right.$ и $\left.\mathrm{NiSO}_{4}\right)$. Концентрация сульфата натрия в приготовленном модельном растворе составляла 400 мг/л, а ионов никеля менялась от 3,13 до 10 мг/л. Такой выбор диапазона концентраций ионов никеля был обусловлен необходимостью полного исключения возможности выпадения их в осадок в виде гидроксида при повышении $\mathrm{pH}$ модельного раствора до значений 7 и 8 [7] в ходе последующих экспериментов по коагуляционной очистке.

Вначале была изучена кинетика удаления ионов никеля образующимся осадком гидроксида железа(III). Целью этих опытов было нахождение времени, необходимого для завершения процесса очистки раствора от ионов никеля при введении в него коагулянта $\mathrm{FeCl}_{3}$. В этих экспериментах в модельный раствор с концентрацией ионов никеля в нём 6,25 мг/л, при непрерывном перемешивании на магнитной мешалке, вводили раствор $\mathrm{FeCl}_{3}(21,3$ г/л) так, чтобы содержание ионов железа(III) в модельном растворе составило 51,16 мг/л. Затем туда же добавляли раствор гидроксида натрия (5-10 г/л) для повышения $\mathrm{pH}$ до значений 7 или 8. После введения щёлочи модельный раствор продолжали перемешивать ещё в течение 30, 60 и 120 мин. При этом его $\mathrm{pH}$ поддерживали на постоянном значении (7 или 8) раствором $\mathrm{NaOH}$. Затем перемешивание прекращали и образовавшийся осадок гидроксида железа(III) отделяли от раствора фильтрованием через бумажный фильтр. В фильтрате определяли остаточное содержание ионов никеля и железа(III).

При исследовании удаления ионов никеля образующимся осадком гидроксида железа(III) в модельный раствор с заданной концентрацией ионов никеля в нём, при непрерывном перемешивании магнитной мешалкой, вводили раствор $\mathrm{FeCl}_{3}$, а следом добавляли раствор $\mathrm{NaOH}$ (5-10 г/л) до значения $\mathrm{pH}$ равного 7 или 8. После введения щёлочи модельный раствор продолжали перемешивать ещё в течение 60 мин. При этом его рН также под- 
держивали на постоянном значении (7 или 8). Затем перемешивание прекращали и, как и выше, производили фильтрование раствора через бумажный фильтр. В фильтрате также определяли остаточную концентрацию ионов никеля. Было выполнено несколько серий таких опытов с начальной концентрацией ионов железа(III) в модельном растворе 12,$18 ; 25,58 ; 51,16$ и 100 мг/л, и концентрацией ионов никеля в нём 3,$13 ; 6,25$ и 10 мг/л.

Объём раствора $\mathrm{NaOH}$, необходимый для подщелачивания модельного раствора до значений $\mathrm{pH}$ равных 7 или 8, определяли в предварительных экспериментах.

Величину рН во всех опытах контролировали и поддерживали на постоянном уровне с помо-

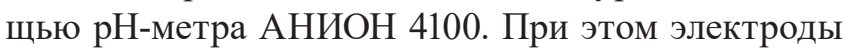
pH-метра были постоянно погружены в модельный раствор в течение всего эксперимента.

Фильтрование растворов производили с помощью бумажного фильтра «синяя лента». Длительность фильтрования составляла около 30 мин.

При определении концентрации ионов никеля в растворе, чтобы исключить возможное искажение результатов анализа при фильтровании изза сорбции части ионов никеля на бумажном фильтре, первые порции отфильтрованных растворов объёмом около 50 мл отбрасывали и для анализа брали оставшиеся объёмы фильтратов. Определение концентрации ионов никеля производили на фотоколориметре КФК-2 фотоколориметрическим методом с диметилглиоксимом [8]. Всего делали по три параллельных определения концентрации ионов никеля в растворе. Полученные результаты усредняли.

Содержание ионов железа(III) в растворе, а также в некоторых случаях ионов никеля, определяли на атомно-эмиссионном спектрометре с индуктивно связанной плазмой ОРТІМА 8000 фирмы Perkin Elmer (USA-Canada) .

\section{Обсуждение полученных результатов}

Кинетика снижения концентрации ионов никеля в модельном растворе при образовании в нём осадка гидроксида железа(III) показана на рис. 1. Как видно, уже через 30 мин с начала процесса остаточная концентрация ионов никеля в растворе как при $\mathrm{pH}=7$, так и при $\mathrm{pH}=8$ практически выходит на равновесное значение и в дальнейшем уже почти не меняется. Это свидетельствует о завершении процессов очистки, а также об окончании образования и формирования осадков гидроксидов железа(III). Последнее также подтверждают и результаты анализа растворов на содержание в них ионов железа(III). Так, через 30 мин с начала про- цесса осаждения концентрация ионов железа(III) в растворе как при $\mathrm{pH}=7$, так и при $\mathrm{pH}=8$ не превышала 0,1 мг/л.

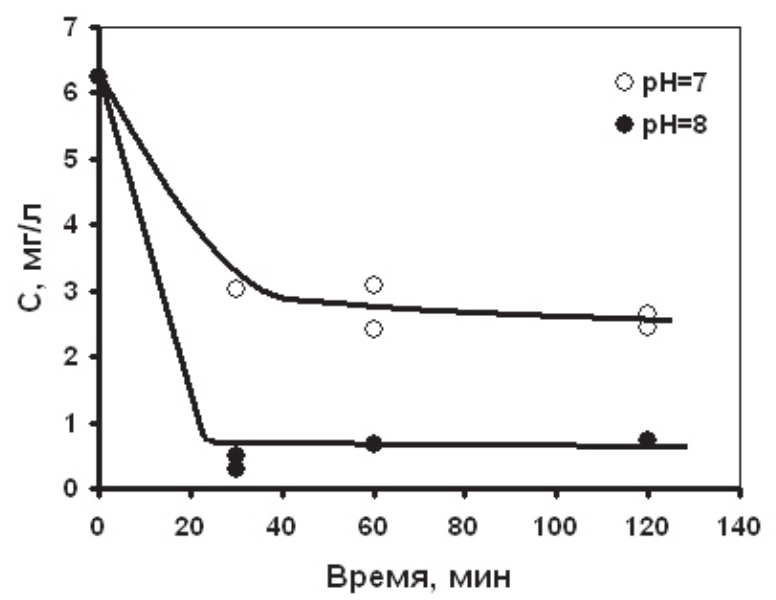

Рис. 1. Зависимость остаточной концентрации ионов никеля в модельном растворе при образовании в нём осадка гидроксида железа(III) от длительности перемешивания раствора и его рН

Начальная концентрация ионов железа(III) в растворе была равна 51,16 мг/л. С-концентрация ионов никеля в растворе

Из рис. 1 видно, что при осаждении осадка гидроксида железа(III) при $\mathrm{pH}=7$ концентрация ионов никеля в модельном растворе снижалась примерно в два раза, с 6,25 мг/л до 2,41-3 мг/л, а при $\mathrm{pH}=8-$ почти в 10 раз, с 6,25 мг/л до 0,28-0,72 мг/л.

С учётом зависимостей на рис. 1 , в дальнейших экспериментах длительность перемешивания модельного раствора с образующимся осадком гидроксида железа(III) была увеличена до 60 мин, чтобы гарантировано завершать эти процессы в равновесных условиях.

Изменение остаточной концентрации ионов никеля в модельном растворе при образовании в нём осадка гидроксида железа(III) при $\mathrm{pH}=7$ показано на рис. 2. Как видно, с увеличением концентрации ионов железа(III), введённых в раствор вначале опыта, остаточная концентрация ионов никеля в нём последовательно уменьшалась. Так, при начальной концентрации железа(III) в растворе 100 мг/л концентрация ионов никеля в нём снижалась с 10 мг/л до 3,18 мг/л, с 6,25 мг/л до 2,16-2,3 мг/л и с 3,13 мг/л до 0,38-0,55 мг/л (рис. 2).

Аналогичная картина наблюдается и при $\mathrm{pH}=8$ (рис. 3). Однако, как видно, в этом случае происходит более сильно понижение остаточной концентрации ионов никеля в растворе, что согласуется с данными на рис. 1. Так, при начальных 
концентрациях ионов железа(III) и никеля в модельном растворе 51,16 и 3,13 мг/л соответственно, остаточная концентрация ионов никеля в нём в конце эксперимента не превышала 0,1 мг/л. В то время как в аналогичном опыте при $\mathrm{pH}=7$ остаточная концентрация ионов никеля в модельном растворе была на порядок выше и составляла 1 мг/л (рис. 2).

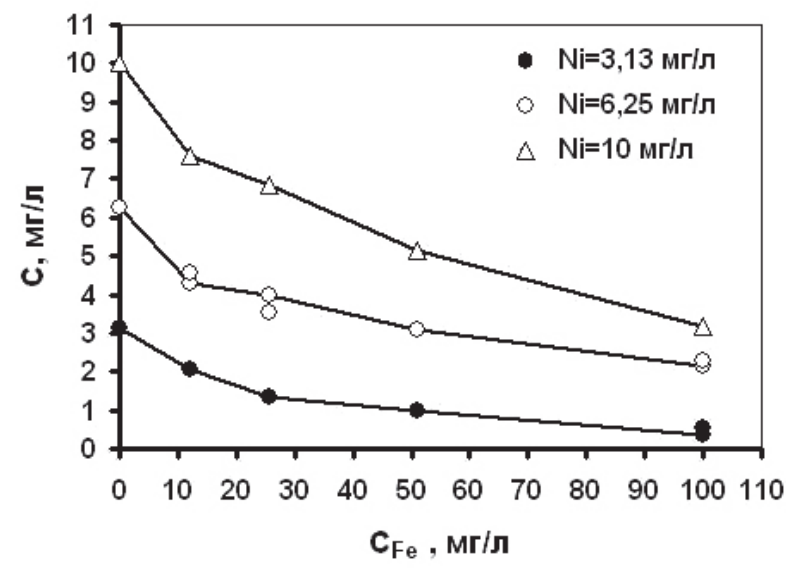

Рис. 2. Изменение остаточной концентрации ионов никеля в модельном растворе при образовании в нём при рН = 7 осадка гидроксида железа(III)

$C_{F e}-$ начальная концентрация ионов железа(III) в растворе

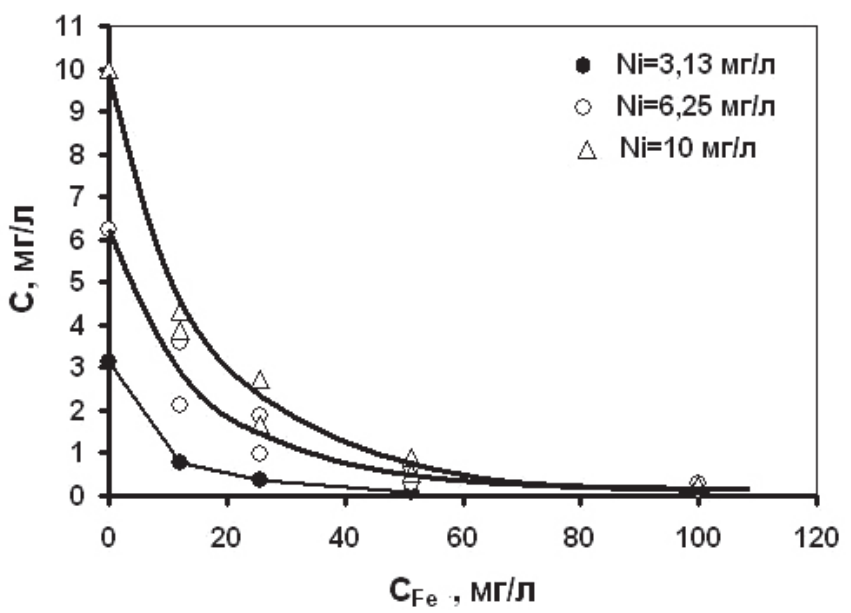

Рис. 3. Изменение остаточной концентрации ионов никеля в модельном растворе при образовании в нём при рН $=8$ осадка гидроксида железа(III)

Можно предложить два объяснения наблюдаемого снижения концентрации ионов никеля в модельном растворе.

1. При образовании осадка гидроксида железа(III) происходит соосаждение ионов никеля с этим осадком за счёт протекания процесса хемо- сорбции, в результате которого осадок гидроксида железа(III) необратимо поглощает ионы никеля из раствора путём образования с ними смешанного соединения или частичного включения их в свою структуру с образованием твёрдого раствора.

2. Снижение концентрации ионов никеля в модельном растворе обусловлено их адсорбцией на поверхности образующегося осадка гидроксида железа(III).

В последнем случае изменение концентрации ионов никеля в растворе при образовании в нём разных количеств осадка гидроксида железа(III) должно описываться известными изотермами адсорбции. При этом следует, конечно, принять во внимание возможное искажение этих зависимостей из-за особенностей формирования осадка гидроксида железа(III). В частности, на его морфологию и удельную поверхность сильное влияние должен оказывать способ создания пересыщение в растворе (концентрации реагентов, условия их смешения и т.п.).

В наших экспериментах пересыщение создавалось за счёт добавления в модельный раствор щёлочи при его перемешивании магнитной мешалкой. Понятно, что полной воспроизводимости условий перемешивания и подачи щёлочи в модельный раствор от опыта к опыту добиться было очень трудно. Поэтому возможен существенный разброс экспериментальных точек на рассчитанных изотермах сорбции.

Изотермы сорбции ионов никеля на образующемся осадке гидроксида железа(III) показаны на рис. 4 и 5. Отметим, что величина сорбции $A$ на этих рисунках имеет размерность мг/(мг $\mathrm{Fe})$. Это означает, что расчёт сделан на начальную концентрацию ионов железа(III) в растворе, а не на концентрацию в нём осадка гидроксида железа(III), который в данном случае является сорбентом:

$$
A=\frac{C_{i n}-C}{C_{F e}}
$$

где $C_{\text {in }}-$ начальная концентрация ионов никеля в растворе, мг/л.

Такой выбор расчёта величины $A$ обусловлен удобством последующего использования полученных результатов в технологических расчётах.

Из рис. 4 и 5 следует, что, несмотря на ожидаемый значительный разброс экспериментальных точек, полученные зависимости можно отнести к типичным изотермам L-типа. Такой тип изотерм сорбции обычно хорошо описывается классическим уравнением Ленгмюра для мономолекулярной адсорбции [9]: 


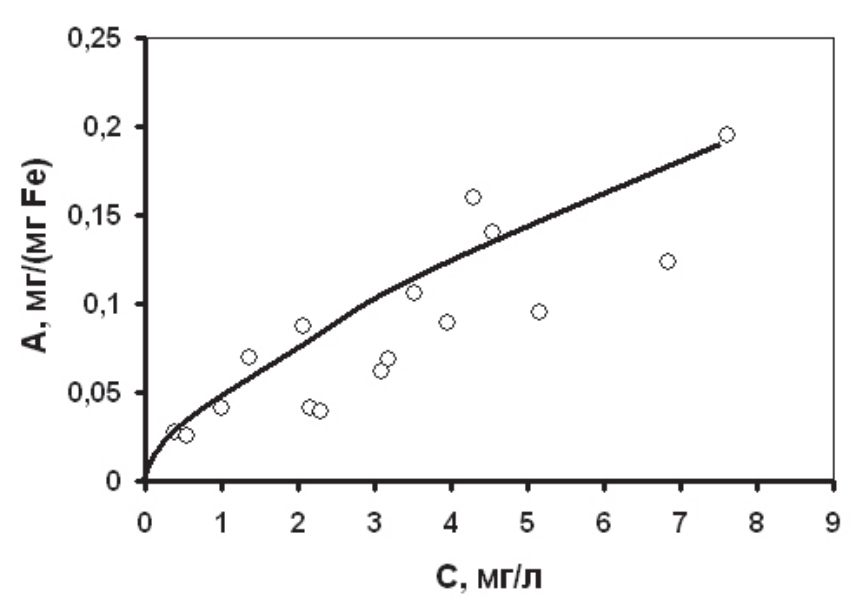

Рис. 4. Зависимость величины сорбции ионов никеля на образующемся при рН $=7$ осадке гидроксида железа(III) от их остаточной концентрации в растворе

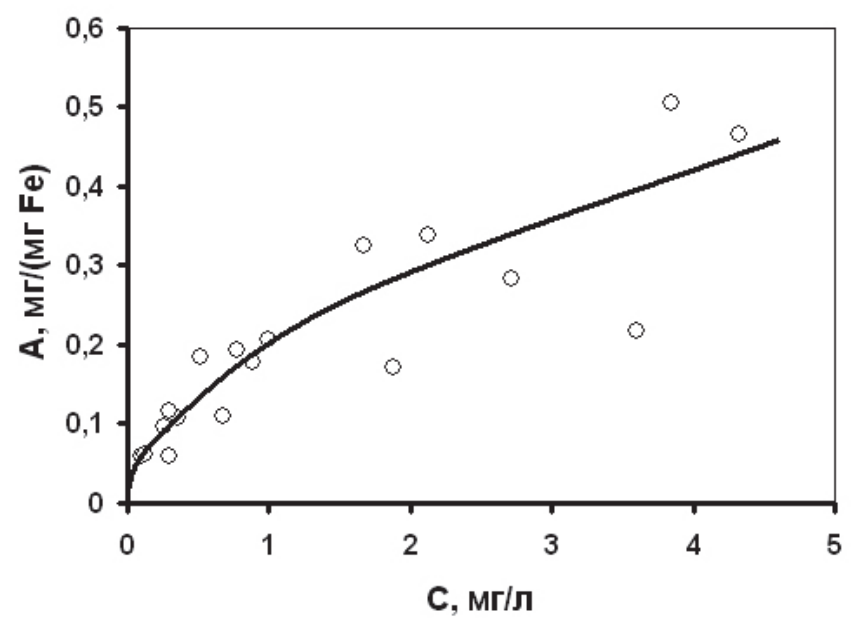

Рис. 5. Зависимость величины сорбции ионов никеля на образующемся при $\mathrm{pH}=8$ осадке гидроксида железа(III) от их остаточной концентрации в растворе

$$
A=A_{\infty} \frac{K_{L} \cdot C}{1+K_{L} \cdot C}
$$

где $A_{\infty}$ - ёмкость адсорбционного монослоя сорбента, мг/(мг $\mathrm{Fe}) ; K_{L}$ - константа адсорбционного равновесия, л/мг.

Экспериментальные данные по сорбции ионов никеля образующимся в растворе осадком гидроксида железа(III) при рН 7 и 8 в координатах уравнения (2) показаны на рис. 6 и 7.

Видно, что экспериментальные точки на рис. 6 и 7 могут быть аппроксимированы прямыми. Это

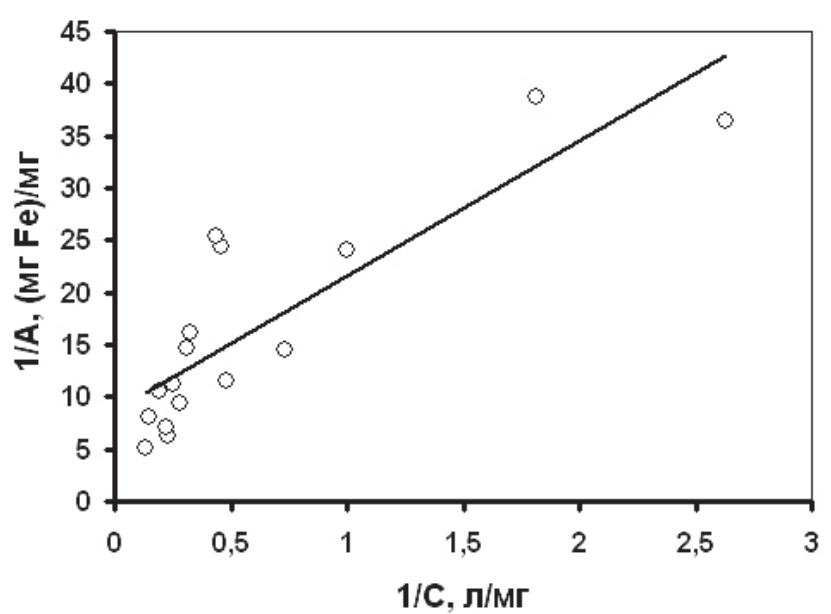

Рис. 6. Экспериментальные данные по сорбции ионов никеля образующимся в растворе при рН = 7 осадком гидроксида железа(III) в координатах уравнения (2)

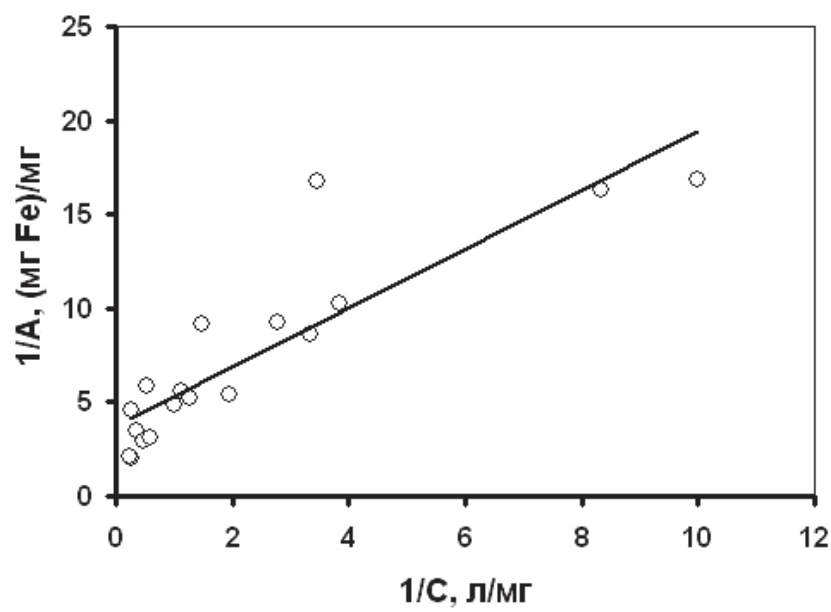

Рис. 7. Экспериментальные данные по сорбции ионов никеля образующимся в растворе при $\mathrm{pH}=8$ осадком гидроксида железа(III) в координатах уравнения (2)

свидетельствует о том, что поглощение ионов никеля образующимся в модельном растворе осадком гидроксида железа(III) может быть с удовлетворительной точностью описано изотермой Ленгмюра. Параметры этого уравнения, рассчитанные по полученным экспериментальным данным приведены в табл. 1.

Уравнение Ленгмюра предполагает наличие динамического равновесия между сорбентом и сорбатом и не может описывать экспериментальные данные при протекании процесса хемосорбции. Поэтому можно сделать вывод, что 
Зависимость параметров уравнения Ленгмюра при адсорбции ионов никеля на образующемся в растворе при рН 7 и 8 осадке гидроксида железа(III). R - коэффициент корреляции

\begin{tabular}{cccc}
\hline $\mathrm{pH}$ & $A_{\infty}, \mathrm{M \Gamma} /(\mathrm{м \Gamma} \mathrm{Fe})$ & $K_{L}$, л/мг & $\mathrm{R}$ \\
\hline 7 & 0,116 & 0,668 & 0,86 \\
8 & 0,264 & 2,425 & 0,88 \\
\hline
\end{tabular}

снижение концентрации ионов никеля в модельном растворе обусловлено в основном их адсорбцией на поверхности образующегося осадка гидроксида железа(III). При этом, конечно, не исключено частичное соосаждение ионов никеля с гидроксидом железа(III) за счёт образования смешанного соединения, например, феррита никеля, но вклад этого хемосорбционного процесса является, повидимому, небольшим.

Полученные экспериментальные результаты могут быть использованы для коагуляционной очистки загрязнённых растворов от ионов никеля с помощью хлорида железа(III). Для этой цели уравнение (2), с учётом формулы (1), может быть приведено к виду:

$$
C=C_{i n}-\frac{A_{\infty} \cdot K_{L} \cdot C}{1+K_{L} \cdot C} C_{F e}
$$

После ряда преобразований выражения (3) получается обычное полное квадратное уравнение, решением которого относительно С являются два корня, но из них по физическому смыслу подходит только один:

$$
C=\frac{1}{2 K_{L}}\left(-b+\sqrt{b^{2}+4 K_{L} C_{i n}}\right)
$$

где $\mathrm{b}=1-\mathrm{K}_{\mathrm{L}} \cdot \mathrm{C}_{\text {in }}+\mathrm{A}_{\infty} \cdot \mathrm{K}_{\mathrm{L}} \cdot \mathrm{C}_{\mathrm{Fe}}$.

Формула (4) позволяет подобрать концентрацию коагулянта $\mathrm{FeCl}_{3}$, необходимую для очистки загрязнённого раствора от ионов двухвалентного никеля до требуемой их остаточной концентрации в растворе.

Отметим также, что из табл. 1 видно, что гидроксид железа(III) обладает существенной адсорбционной ёмкостью по отношению к ионам никеля. Так, если пересчитать ёмкость его монослоя в привычные единицы, на грамм гидроксида железа(III), выполняющего в данном случае роль сорбента, то для рН 7 и 8 получим значения 60,8 и 138,3 мг/г соответственно. Сравнение с литературными данными показывает, что сорбционная ёмкость многих минеральных и угольных сорбен- тов по ионам никеля примерно на порядок ниже этих значений $[10,11]$.

\section{Заключение}

Таким образом, использование в качестве коагулянта хлорида железа(III) позволяет очищать загрязнённые растворы не только от нерастворимых грубодисперсных и коллоидных примесей, но также и от присутствующих в них ионов никеля. Удаление ионов никеля из раствора образующимся в нём осадком гидроксида железа(III) при рН 7 и 8 с удовлетворительной точностью описывается уравнением Ленгмюра для мономолекулярной адсорбции. Это указывает на преобладание адсорбционного процесса при соосаждении ионов никеля с осадком гидроксида железа(III). Сорбционная ёмкость гидроксида железа(III) по ионам никеля почти на порядок превосходит аналогичную величину для ряда минеральных и угольных сорбентов. Наиболее полно удаление ионов никеля из раствора происходит при осаждении гидроксида железа(III) при $\mathrm{pH}=8$. Полученные данные позволяют подбирать требуемую концентрацию коагулянта $\mathrm{FeCl}_{3}$ для достижения заданной глубины очистки загрязнённых растворов от ионов никеля.

Работа выполнена в соответствии с государственным заданием и планами НИР ИХТТ УрО РАН, а также при финансовой поддержке Правительства Свердловской области и РФФИ (грант № 20-48-660038).

\section{Лumepamypa}

1. Бабенков Е.Д. Очистка воды коагулянтами. М.: Наука, 1977. - $356 \mathrm{c}$.

2. Драгинский В.Л., Алексеева Л.П., Гетманцев С.В. Коагуляция в технологии очистки природных вод. М.: Науч. изд. 2005. -576 c.

3. Качалова Г.С. Вода и экология: проблемы и решения. 2019. № 2 (78). С. 32-39. DOI: 10.23968/23053488.2019.24.2.32-39

4. Соломенцева И.М., Величанская Л.А., Герасименко Н.Г. Химия и технология воды. 1991. Т. 13. №5. C. 517-534. 
5. Бойкова Т.Е., Богданович Н.И., Воронцฺов К.Б., Мауричева Т.С., Долгобородова С.Н., Короткий В.П. Экология и промышленность России. 2019. Т. 23. №2. C. 30-35. DOI: 10.18412/1816-0395-2019-02-3035 .

6. Линников О.Д., Родина И.В., Аксёнов В.И., Никулин B.A., Пеиура C.C. Водоснабжение и санитарная техника. 2009. № 12. С. 38-41.

7. Лурье Ю.Ю. Справочник по аналитической химии. Москва. Химия. 1989. 448 с.

8. Новиков Ю.В., Ласточкин К.О., Болдина 3.Н. Методы исследования качества воды водоёмов. Изд. 2-е, дополненное и переработанное. М.: Медицина, $1990.400 \mathrm{c}$.

9. Фролов Ю.Г. Курс коллоидной химии (Поверхностные явления и дисперсные системы). М.: Химия, 1982. $-400 \mathrm{c}$.

10. Линников О.Д., Родина И.В. Химическая технология. 2020. T. 21. №5. C. 199-204. DOI: $10.31044 / 1684-$ 5811-2020-21-5-199-204.

11. Гимаева А.Р., Валинурова Э.Р., Игдавлетова Д.К., Кудашева Ф.X. Сорбционные и хроматографические процессы. 2011. Т. 11. №3. С. 350-356.

\section{References}

1. Babenkov E.D. Ochistka vody koagulyantamy. M.: Nauka, 1977 - 356 p.

2. Draginskii V.L., Alexeeva L.P., Getmantcev S.V. Koagulyatciya $\mathrm{v}$ tehnologii ochistki prirodnyh vod. M.: Nauch.izd. 2005, - 576 p.
3. Kachalova G.S. Coagulation and sorption treatment of wastewater. Water and Ecology. 2019. № 2. (78). P. 3239. DOI: 10.23968/2305-3488.2019.24.2.32-39.

4. Solomentceva I.M., Velichanskaya L.A., Gerasimenko N.G. Himiya i Tehnologiya vody. 1991. V. 13. №5. P. 517-534.

5. Boykova T.E., Bogdanovich N.I., Vorontsov K.B., Mauricheva T.S., Dolgoborodova S.N., Korotky V.P. Use as an iron (iii) sulfate coagulant in water treatment in the pulp and paper industry. Ecology and Industry of Russia. 2019. V. 23 № 2. P. 30-35. DOI: 10.18412/18160395-2019-02-30-35.

6. Linnikov O.D., Rodina I.V., Aksyonov V.I., Nikulin V.A., Petcura S.A. Vodosnabgenie i sanitarnaya tehnika. 2009. № 12. P. 38-41.

7. Lurie Yu.Yu. Spravochnik po analiticheskoy himii. Moskwa. Himiya. 1989. 448 p.

8. Novikov Yu.V., Lastochkin K.O., Boldina Z.N. Metody issledovaniya kachestva vody vodoyomov. Izd. 2-e, dopolnennoe I pererabotannoe. M.: Meditcina, 1990. 400 p.

9. Frolov Yu.G. Kurs kolloidnoi himii (Poverhnostnye yavleniya I dispersnye sistemy). M.: Himiya, 1982, $400 \mathrm{p}$.

10. Linnikov O.D., Rodina I.V. Sorption of nickel(ii) ions by filter material MS. Chemical Technology. 2020. V. 21. №5. P. 199-204. DOI: 10.31044/1684- 5811-2020-215-199-204.

11. Gimaeva A.R., Valinurova E.R., Igdavletova D.K., Kudasheva F.Ch. Sorption of heavy metals ions from water by the activated carbon adsorbents. Sorption and Chromatography processes. 2011. V. 11. №3. P. 350-356. 